\title{
Relendo Walter Benjamin: etnografia da música, disco e inconsciente auditivo*
}

\author{
André-Kees de Moraes Schouten \\ Mestrando em Antropologia Social pela FFLCH/ \\ USP, membro do Núcleo de Antropologia da \\ Performance e do Drama (NAPEDRA/USP) e \\ bolsista FAPESP.
}

Artigo aceito para publicação em 05/09/05

resumo Conforme Walter Benjamin apontou em seu ensaio "A obra de arte na era da sua reprodutibilidade técnica", diante das modernas técnicas de reprodução a arte vê-se destituída de sua aura, fundamento de sua autenticidade. Para o autor, só seria possível mostrar as condiçóes sociais de tal decadência entendendo-a não como perda de importância da arte no mundo moderno, mas sim como alteraçóes no medium de percepção contemporâneo. Tratando do cinema e da fotografia, diz Benjamin que a reprodução técnica tanto autonomiza a arte de sua existência no ritual, inserido-a agora numa práxis política, como as obras que reproduz permitem acessar o inconsciente óptico da sociedade moderna. Partindo das sugestivas idéias deste autor, e tomando como objeto de reflexão o disco, procuramos nesse trabalho explorar algumas possibilidades de tratamento etnográfico do material fonográfico no âmbito de uma etnografia da música, procurando neste material algo além de sua capacidade de testar hipóteses.

palavras-chave teoria crítica e etnografia da música, reprodução técnica da música (disco), medium de percepção contemporâneo, inconsciente auditivo.

\author{
Giovanni Cirino \\ Mestrando em Antropologia Social pela FFLCH/ \\ USP, membro do Núcleo de Antropologia da \\ Performance e do Drama (NAPEDRA/USP) e \\ membro do Grupo de Som e Música em Antro- \\ pologia (SOMA/USP).
}

abstract According to Walter Benjamin's essay "The work of art in the age of mechanical reproduction" the art's aura, its autenticity basis, is destroyed facing modern techniques of reproduction. For this author, we can show the social conditions of this decadence understanding it not as a reduction of the importance of the art in the modern world, but as alterations on the contemporary perception medium. Analysing the cinema and the photography, Benjamin writes that the thecnical reproduction emancipates the art from its parasitary existence inside the ritual, and puts it in the political praxis, as well as the works that it reproduces give access to the optical unconscious of the modern society. From the suggestive ideas of this author, and assuming the record as reflection object, we would like to explore some possibilities of ethnographic treatment for phonographic material, in the range of ethnography of music, searching in this material something beyond its capability to test hypothesis.

keywords critic theory and ethnography of music, technical reproduction of music (record), contemporary perception medium, aural unconscious.

Elizabeth Travassos (Instituto Villa-Lobos - PPGM/ UNIRIO) e Santuza Cambraia Naves (PUC/RJ - NUM/CESAP/UCAM). Olinda, junho de 2004. 


\section{Introdução}

Apesar de realizarmos pesquisas um tanto distintas (as práticas da música popular instrumental na cidade de São Paulo e a experiência do sertão na obra fonográfica de Elomar Figueira Mello), temos nos discos um importante material, o que nos colocou às voltas com um problema comum: ${ }^{1}$ seria possível um tratamento etnográfico deste material fonográfico ou, em outras palavras, que lugar ele ocuparia no contexto de um empreendimento etnográfico? $\mathrm{O}$ que por ora apresentamos são algumas ponderaçóes acerca das possibilidades de tal tratamento no âmbito de uma etnografia da música.

De início, apresentamos a maneira como Anthony Seeger (1992) e John Blacking (1995) entendem a noção de etnografia da música, salientando a posição que reservam aos discos e outros meios técnicos de captação e reprodução sonora. Para esses autores, dada a capacidade que trazem de iludir quanto à essência humana da música (o fazer musical), tais meios não forneceriam chaves significativas para a compreensão da natureza do discurso musical, servindo apenas como ferramentas no teste de hipóteses junto aos músicos e à sua audiência. Indagamos entáo se náo seria possível tratar esta ilusão auditiva produzida pelos meios técnicos como constituinte do fazer musical contemporâneo, tentando trazer os discos para o foco central do empreendimento etnográfico. Nesta tentativa é que encontramos amparo na (re)leitura de Walter Benjamin, cujas idéias são alvo de atençáo no segundo momento do texto. ${ }^{2}$

1. Agradecemos ao nosso orientador, professor John Cowart Dawsey, por nos ter apontado esta 'comunhão problemática', sugerindo que trabalhássemos juntos sobre ela. $\mathrm{O}$ presente trabalho surge, então, como tentativa de responder ao desafio apontado.

2. Neste sentido, o presente trabalho dialoga com o ensaio do antropólogo José Jorge de Carvalho, "Transformaçôes da sensibilidade musical contemporânea"
No ensaio "A obra de arte na era da sua reprodutibilidade técnica" ([1936] 1985d; [1955] 1992), o crítico alemão propóe que a câmara seria capaz de nos conduzir ao inconsciente óptico da sociedade contemporânea, uma vez que sua linguagem é essencialmente diferente daquela do olho humano. É neste sentido que procuramos reler Walter Benjamin, interrogando pela pertinência de se pensar a reprodução técnica como capaz de produzir efeito análogo na apercepção musical, ou seja, se a diferença de linguagem entre gravador e ouvido humano náo nos permitiria acesso ao inconsciente auditivo. Para tanto, resgatamos também o diálogo com seu parceiro intelectual Theodor Wiesengrund Adorno em "Idéias para a sociologia da música" ([1959] 1983a) e "O Fetichismo na música e a regressão da audição" ([1963] 1983b), procurando passar da imagem ao som tecnicamente reprodutível.

Feita esta arriscada incursão em certos campos de caça da teoria crítica, procurando salientar, no diálogo estabelecido entre Adorno e Benjamin, como a reprodução técnica (visual/musical), na sua diferença de linguagem, se relaciona com o acesso ao inconsciente (óptico/sonoro), passamos ao terceiro e último momento, buscando retornar a paragens mais antropológicas.

$\mathrm{Na}$ leitura dos autores acima, foi possível perceber que eles lançam mão de certas noçóes da psicanálise para enfrentar os problemas de comunicação colocados pelas inovaçóes técnicas, pela reprodução técnica. $\mathrm{Na}$ antropologia moderna, um dos primeiros a indicar uma aproximação entre etnologia e psicanálise foi Marcel Mauss, como nos lembra Claude LéviStrauss em sua célebre "Introdução à obra de

(1999), onde procura refletir sobre tais mudanças a partir das profundas transformaçōes na tecnologia da produção musical contemporânea. Como aqui, o autor também recorre aos pensamentos de, entre outros, Benjamin e Adorno. 
Marcel Mauss" ([1950] 2003), afirmando ser esta uma das características mais significativas do modernismo do outro. ${ }^{3}$ Mas se é possível relacionar os pensamentos de Mauss e Benjamin a partir da psicanálise, uma outra opção, talvez mais frutífera para este trabalho, seja enfocar as maneiras como ambos encaram as relaçóes entre técnica e corpo, na tentativa de entender os problemas que a linguagem técnica coloca à comunicação humana.

Ao final retornamos ao problema inicial, qual seja, a compatibilizaçáo entre discos e etnografia da música, procurando costurar algumas considerações acerca das possibilidades de tratamento etnográfico do material fonográfico, numa perspectiva que incorpore a ilusão auditiva trazida pela técnica de reprodução sonora como parte do fazer musical contemporâneo.

\section{Com Seeger e Blacking: discos e etno- grafia da música}

Entendemos etnografia da música nos termos definidos por Anthony Seeger e John Blacking, ou seja, como "(...) escrita sobre as maneiras que as pessoas fazem música” (Seeger 1992: 89, tradução nossa), prática que exige do pesquisador uma abordagem atenta ao fazer musical, obrigando-o a incluir na sua visada não só os sons produzidos, mas também os seres humanos envolvidos na sua realização (dos músicos à audiência), perseguindo as maneiras como concebem, produzem e apreciam estes sons, assim como influenciam outros indivíduos, grupos, processos sociais e musicais,

3. "Assim, Mauss náo apenas estabelece o plano de trabalho que será, de forma predominante, o da etnografia moderna ao longo dos dez últimos anos, mas percebe ao mesmo tempo a conseqüência mais significativa dessa nova orientaçáo, isto é, a aproximação entre etnologia e psicanálise” (Lévi-Strauss [1950] 2003: 13). Um pouco mais à frente, Lévi-Strauss adverte ainda que "O problema etnológico é portanto, em última análise, um problema de comunicaçáo (...)" (idem: 29). sendo a música entendida como um sistema de comunicação utilizado pelos membros de uma comunidade para se comunicarem com outros membros (Seeger 1992; Blacking 1995).

Essa combinação - discos e etnografia da música - a princípio pode soar estranha, pois se são as pessoas que fazem música para outras ouvirem, a atenção demasiada aos discos perderia de vista o fazer musical. Isto porque, segundo esses autores, todo o aparato técnico-eletrônico de captação e reprodução sonora utilizado em nossa sociedade, captando e reproduzindo apenas o aspecto acústico da música, criariam uma ilusão auditiva (Seeger 1992) ou de objetividade (Blacking 1995), como se os sons pudessem ser produzidos independentemente da ação humana, confundindo quanto à

(...) essência do fazer musical e da compreensão musical [que] são os atos humanos de produzir sentido com os símbolos musicais através da composição, da performance e da audição (Blacking 1995: 229; tradução nossa).

De acordo com os autores, então, dada sua característica ilusória, os meios técnicos de registro e reprodução sonora não são capazes de fornecer chaves significativas para a compreensão da natureza do discurso musical - quando muito são boas ferramentas de pesquisa, pela sua capacidade de testar hipóteses (Blacking 1995); bem como são em parte responsáveis pela confusão entre música e som na sociedade contemporânea (Seeger 1992).

Mas é graças a esses meios técnicos que nós, pelo menos desde meados do século XX, ouvimos grande parte da música que conhecemos: músicas do mundo inteiro nos são acessíveis por meio de discos, fitas e rádios. E mesmo que aquela ilusão auditiva não seja característica da própria música, mas um aspecto dos meios técnicos utilizados, é preciso levá-la em consideração - e não descartá-la - para tentar 
entender o que seria fazer música com o auxílio de tais meios. Em outras palavras, mais do que iludir quanto à essência humana da música, a ilusão auditiva que acompanha a técnica de reproduçáo participa criativamente do fazer musical contemporâneo, provocando alteraçóes na concepçáo, na produção e na apreciação das músicas que reproduz.

Como certa vez afirmou Walter Benjamin ([1929] 1985a), de nada adianta "apontar no enigmático seu lado enigmático", já que o mistério só é desvelado na medida que o encontramos no cotidiano, graças a uma ótica dialética que permita ver "o cotidiano como impenetrável e o impenetrável como cotidiano". ${ }^{4}$ Em busca do aspecto produtivo que a ilusão auditiva assume quando a música passa a ser tecnicamente reprodutível é que nos propusemos a reler Walter Benjamin. Partindo de uma afirmação feita em seu ensaio "A obra de arte na era da sua reprodutibilidade técnica" ([1936] 1985d; [1955] 1992), indagamos: da mesma maneira que a “(...) câmara leva-nos ao inconsciente óptico, tal como a psicanálise ao inconsciente das pulsóes (...)" ([1936-1955] 1992: 105), o gravador seria capaz de nos conduzir ao inconsciente auditivo?

\section{Com Benjamin e Adorno: reprodução técnica, inconsciente ótico e apercepção}

No ensaio acima referido, dirigindo a palavra aos críticos de arte de sua época, Walter Benjamin defende que os valores artísticos encerrados na fotografia, mas sobretudo no cinema, já não são apreensíveis pelos conceitos tradicionais - criatividade e gênio, validade eterna e estilo etc. -, exigindo a formulação de

4. A este procedimento Walter Benjamin deu o nome de "iluminação profana", que não será tratado no presente trabalho. Para uma exposição de tal procedimento, ver o ensaio "O surrealismo - o último instantâneo da inteligência européia” ([1929] 1985a). novos conceitos em teoria da arte. Para ele, isto só é possível entendendo quais as novas exigências que o cinema, fruto da técnica de reprodução artística, impóe ao modo de percepção do homem contemporâneo (condicionado natural e historicamente). Segundo o autor, a apercepção 5 de um filme exige de seu espectador um estado de descontração, atitude bem diferente da atençáo e do recolhimento diante de um quadro, por exemplo. A atitude crítica que o cinema requer de seu público se dá na descontraçáo, sendo o público caracterizado por ele numa fórmula um tanto paradoxal: um examinador distraído (Benjamin [1936] 1985d; [1955] 1992).

Para o autor, o que caracteriza o filme não é só a forma como o homem se apresenta diante do equipamento de registro, mas também como, com a ajuda deste, reproduz o seu meio ambiente. Embora reconhecendo que a psicologia do desempenho ilustra a capacidade de teste do equipamento, ele prefere abordar tal fato a partir de um diálogo com a psicanálise:

(...) o cinema enriqueceu o nosso horizonte de percepção com métodos que podem ser ilustrados pela teoria freudiana (Benjamin [1955] 1992: 102).

Vale lembrar que Walter Benjamin não está propondo nenhuma espécie de psicanálise do social a ser feita através do cinema, mas que as alteraçóes produzidas pela linguagem cinematográfica na percepção que o homem contemporâneo tem de si e do seu meio (natural e histórico) são comparáveis às alteraçôes que a psicanálise trouxe para a compreensão que o indivíduo tem de sua psique. Ou seja, da mesma maneira que a psicanálise tornou possível

5. apercepçáo s. f. 1. Ação ou faculdade de perceber. 2. Consciência imediata de si e do mundo. 3. Intuição; percepção. (Grande Dicionário Larousse Cultural da Lingua Portuguesa 1999). 
ao indivíduo apreender seu eu mais secreto, tomar consciência das formas de atividade de seu inconsciente individual, o cinema possibilitou ao homem contemporâneo acesso ao inconsciente da sociedade onde está inserido.

Para o autor, assim como o trabalho de Freud $^{6}$ permitiu isolar e analisar o que antes passava despercebido no fluxo do perceptível, como um lapso numa conversa que transcorre superficialmente, levando agora à abertura de perspectivas profundas, o cinema teria como conseqüência um aprofundamento semelhante da apercepção, já que os desempenhos em um filme podem ser analisados com maior exatidão e sob mais pontos de vista do que aqueles apresentados num quadro ou no palco. Afirma então que através dos grandes planos, do realce de pormenores escondidos nos aspectos do cotidiano, e na exploração dos ambientes mais banais pela direção genial da objetiva, o cinema foi capaz de aumentar a compreensão das imposiçóes que regem nossa existência, assim como nos assegurou um novo campo de ação imenso e insuspeitado. E não apenas porque a câmara e seus meios auxiliares revelam motivos conhecidos em movimento, mas antes por descobrir nesses movimentos conhecidos outros, desconhecidos. E isso torna compreensível que a natureza da linguagem da câmara seja diferente da linguagem do olho humano. Diferente, sobretudo, porque ao invés de um espaço preenchido conscientemente pelo homem, surge um outro preenchido inconscientemente (Benjamin [1936] 1985d; [1955] 1992). ${ }^{7}$

Feita esta rápida apresentaçáo do problema em Benjamin, é possível indagar: a técnica de

6. Benjamin se refere ao "Psicopatologia da Vida Quotidiana”, de Sigmund Freud. Para as relaçôes do pensamento benjaminiano com a teoria freudiana ver o trabalho de Sérgio Paulo Rouanet (1981).

7. Esta discussão já havia sido feita por Benjamin num ensaio anterior: "Pequena história da fotografia" ([1931] 1985b). reprodução sonora teria, na apercepção contemporânea, um efeito análogo à técnica cinematográfica? O ouvinte de discos, fitas e rádios seria capaz de se colocar no mesmo estado de descontração que o cinema exige de seu espectador? E sendo a linguagem do gravador diferente da linguagem do ouvido humano, seria possível falar num espaço sonoro preenchido inconscientemente? Neste ponto a leitura dos textos de Theodor Wiesengrund Adorno nos ajuda nessa difícil passagem da imagem ao som tecnicamente reprodutível. ${ }^{8}$

Para Walter Benjamin, o seu ensaio "A obra de arte na era da sua reprodutibilidade técnica" ([1936] 1985d; [1955] 1992) e o de Adorno "O Fetichismo na música e a regressão da audição" ([1963] 1983b), são duas abordagens diferentes do mesmo fenômeno, onde ele procura articular os momentos positivos daquilo que o outro ressalta como negativos, apontando para uma possível mediação dialética entre seus pontos de vista na análise do filme sonoro. ${ }^{9}$ Esta

8. Para uma brilhante e instigante exposição das convergências e divergências entre os pensamentos de Benjamin e Adorno, neste e noutros 'confrontos' que marcaram ambas as produções, ver o trabalho de Flávio René Kothe (1978).

9. "In my essay ['The Work of Art in the Age of Mechanical Reproduction'] I tried to articulate positive moments as clearly as you managed to articulate negatives ones. Consequently, I see strengths in your study at points where mine was weak. (...) An analysis of the sound film would constitute a critique of contemporary art which would provide a dialectical mediation between your views and mine" (Benjamin [1938] 1994: 140). Como lembrou Flávio René Kothe (1978), tanto Benjamin quanto Adorno, nestes e em alguns outros ensaios da mesma época, tinham como preocupação comum à decadência como problema da arte moderna, apresentando todavia propostas diferentes no enfrentamento da questão. Nas palavras de Flávio Kothe: "Enquanto Adorno enfatiza o desenvolvimento autônomo das técnicas da obra de arte, Benjamin enfatiza a ligação e o condicionamento delas em relação às técnicas de produção social" (1975: 32). 
ida às idéias de Adorno acerca da música contemporânea nos autoriza, na chave da relação entre reprodução técnica e inconsciente, pensar num paralelo auditivo do inconsciente óptico de Benjamin, mas que olhe positivamente para a técnica de reprodução musical, ou seja, vendo a inovação técnica na música não do ponto de vista do desenvolvimento autônomo das técnicas da obra de arte, mas do seu condicionamento em relação às técnicas de produção social.

No referido ensaio, Theodor W. Adorno afirma que a atual música de massas encontra na descontraçáo o seu modo de comportamento perceptivo, lembrando que a observação de Walter Benjamin quanto à apercepção de um filme em estado de distração é válida também para a música ligeira. No entanto, afirma também que, se o filme enquanto totalidade é adequado à apreensão em estado de descontração, a audição desconcentrada torna impossível apreender uma totalidade (Adorno [1963] 1983b). Assim, ao mesmo tempo em que Adorno reconhece a possibilidade da apercepção musical na descontração, ele aponta que, ao contrário do que Walter Benjamin vê no cinema, a técnica de reprodução na música náo se apresenta como um progresso, mas como um retrocesso. ${ }^{10} \mathrm{O}$ autor parece dizer: há um ouvinte descontraído, mas que é incapaz de

10. A título de ilustração da maneira como os autores entendem a relação entre técnica e arte, citamos aqui estes dois trechos: “(...) o conceito de técnica pode ajudar-nos a definir corretamente a relação entre tendência e qualidade (...). Se em nossa primeira formulação dissemos que a tendência política correta de uma obra inclui sua qualidade (...), porque inclui sua tendência (...), é possível agora dizer, mais precisamente, que essa tendência (...) pode consistir num progresso ou num retrocesso da técnica (...)" (Benjamin [1934] 1985c: 122-123); "O que decide se uma determinada técnica pode ser considerada 'racional' e constitui um progresso, é o sentido original, a sua posição no conjunto social e no conjunto da obra de arte concreta e individual" (Adorno [1963] 1983b: 189). atitude crítica semelhante ao espectador distraído do filme.

Neste ponto caberia uma indagação a Adorno: se disco e filme têm seu fundamento na técnica de reproduçáo, e se tanto espectador quanto ouvinte são capazes da apreensão desconcentrada, por que essa apreensão não permite ao último vislumbrar a totalidade? No outro ensaio - "Idéias para a sociologia da música" ([1959] 1983a) - Adorno nos oferece algumas pistas para responder a esta questão. Em suas palavras:

A música, tomada em conjunto, é particularmente apropriada para ideologia, pois a ausência de conceitos permite que os ouvintes se sintam como seres de sentimento, que associem livremente, que pensem o que quiserem. Ela funciona como realização dos desejos, como satisfação substitutiva, mas sem que o mecanismo seja evidente, como o é no filme (Adorno [1959] 1983a: 262).

Em outras palavras, o ouvinte descontraído não é capaz de perceber a totalidade porque o mecanismo de realizaçáo dos desejos não é evidente. E isso acontece, segundo o autor, dada a natureza náo-conceitual da música que, a despeito de sua figura e sentidos próprios, contribui para o que chama de ideologia do inconsciente; e como esfera cultivada da irracionalidade em meio ao mundo racionalizado, ela acaba por justificar a perpetração da irracionalidade global (Adorno [1959] 1983a).

É possível perceber que aqui Adorno está pensando com Max Weber e, seguindo com ele, ressalta que a categoria da racionalizaçáo é decisiva para a sociologia da música, corroborando a tese weberiana de que a história da música ocidental é a de uma progressiva racionalização. ${ }^{11}$ No entanto, lembra o autor

11. Weber, Max. Os Fundamentos Racionais e Sociológicos da Música ([1911] 1995). 
que a racionalização é apenas um de seus aspectos sociais, como a racionalidade ela própria - Aufklärung - é um momento na história da sociedade, e que no interior do movimento progressivo de desencantamento do mundo do qual participou, a música foi também a voz do que ficara para trás no caminho dessa racionalidade, ou do que dela fora vítima. Diz ainda ser esta a contradiçáo social que está no centro da música, e também a tensão da qual a produtividade musical tem-se alimentado na sociedade moderna. Feita esta crítica a Max Weber, o autor então afirma que:

Por seu puro material a música é a arte em que os impulsos pré-racionais e miméticos se afirmam irredutivelmente, entrando ao mesmo tempo em constelação com as tendências ao progressivo domínio da natureza e dos materiais. Daí a sua transcendência em face da engrenagem cotidiana da auto-conservação (...). Se é que efetivamente ela vai além da mera repetição do que já existe, será por essa razão. Mas é pela mesma razão, por outro lado, que ela é táo apropriada à constante reproduçáo da estupidez. $\mathrm{O}$ que faz dela mais que mera ideologia é também o que mais facilita a caricatura ideológica. Como campo delimitado e cultivado da irracionalidade em meio ao mundo racionalizado, ela se transforma no estritamente negativo, tal como é racionalmente planejado, produzido e administrado pela indústria da cultura de massas em nossos dias. Só por força da racionalidade a música pode ultrapassá-la (ibidem).

Para Adorno, então, essa irracionalidade da música socialmente manipulada seria um dos fenômenos que exprimiriam um nexo social de maior alcance: o predomínio da produção. Conceito que para ele náo deve ser posto como absoluto, assim como não deve ser identificado à produçáo social de bens. Tendo isso em mente, afirma ser possível distinguir entre dois momentos da produçáo musical: o da autonomia da exigência expressiva e da lógica do objeto, que diz ser respeitada pelo compositor; e o das leis de produção de bens para o mercado, mesmo que estas possam penetrar nos momentos estéticos mais sublimes. Diz ainda que a tensão entre os dois momentos é essencial na esfera da produção, uma vez que o nexo imanente da motivação musical não corre inteiramente fechado, ou seja, ao mesmo tempo em que a música se desdobra segundo sua própria lei - que é secretamente social -, também é movimentada e desviada no interior do campo das forças sociais.

Daí o autor afirmar a necessidade da dupla abordagem que propóe em sua sociologia da música, fugindo das aproximaçóes externas entre obras do espírito e relaçóes sociais: partindo de uma análise técnica e fisionômica que dá sentido e nome ao momento formal como momento de significação musical e daí passando à sociedade, levando assim com que os constituintes formais da música, sua lógica, falem em termos sociais. E isso não significa procurar elos intermediários entre a música ou o autor de determinada época e a sociedade na qual foi produzida mas, como apontou Gabriel Cohn ao introduzir as idéias de Adorno, significa

(...) procurar a marca dessa sociedade na tessitura das obras mesmas, nos problemas que o compositor enfrentou para dar conta do material musical - ou seja, do conjunto de elementos técnicos e construtivos historicamente constituídos de que dispunha - e nas soluçóes encontradas na efetuação da lógica interna - da 'lei formal'(...) (Cohn 1986: 20).

Mas voltemos ao diálogo com Walter Benjamin. Como transparece nestas palavras de Cohn em referência a Adorno, os dois autores partem da comum idéia que o conteúdo espiritual só se realiza nas obras de arte mediante 
categorias técnicas, ${ }^{12}$ ou seja, pelo agenciamento de técnicas de que o artista dispóe para levar suas aspiraçóes subjetivas a se superar na objetividade do material e da forma. Mas se para Benjamin a técnica de reprodução no cinema constitui um avanço da técnica cinematográfica, para Adorno ela constitui um retrocesso da técnica musical, daí ele chamar a apercepção descontraída da música ligeira de “audição regredida”. Como apontam, tanto o filme quanto a música ligeira ${ }^{13}$ são adequados à apercepçáo em estado de descontração. No entanto, como quer Adorno, só o primeiro possibilita a apreensão de uma totalidade nesse estado, pois só nele o mecanismo inconsciente de realização dos desejos se torna evidente. Em outras palavras, a técnica de reprodução só é tecnicamente conseqüente no

12. É curioso como esta afirmação, a princípio tão "filosófica", "dialética" e "materialista", é próxima daquela feita por Marcel Mauss ao apresentar a importância da noção de habitus que introduz na discussão sociológica: "É preciso ver técnicas e a obra da razão prática coletiva e individual, lá onde geralmente se vê apenas a alma e suas faculdades de repetição" ([1950] 2003a: 404).

13. É preciso considerar que, ao longo dos dois textos, Adorno utiliza diversos adjetivos ao se referir à música - séria, ligeira, de massas, de entretenimento e artística -, que devem ser entendidos não como definiçóes taxativas que separe esta daquela música, e sim como um conjunto de noçóes que devem ser entendidas em suas relaçóes e oposiçóes ao longo do texto. Daí a dificuldade em especificar como ele entende cada uma delas. Mesmo assim é possível dizer, num resumo empobrecedor, que nos dois trabalhos música séria e música ligeira surgem em oposição, sendo a música séria (grande música) entendida por ele como a música tradicional da Europa Ocidental, a música ligeira parece identificada à música popular e em especial ao jazz; a música de entretenimento está associada ao jazz comercial, sendo ao mesmo tempo música ligeira e de massas; e por fim a música artística seria aquela que, realizando uma música de massas tecnicamente conseqüente, afasta-se das massas, em busca de seu próprio destino. cinema porque o espectador é capaz de, pelos valores do sentido, acessar os valores do espírito. Como afirmou Benjamin:

O filme serve para exercitar o homem nas novas percepçóes e reaçóes exigidas por um aparelho técnico cujo papel cresce cada vez mais em sua vida cotidiana. Fazer do gigantesco aparelho técnico do nosso tempo o objeto das inervaçóes humanas - é essa a tarefa histórica cuja realização dá ao cinema seu verdadeiro sentido (Benja$\min$ [1936] 1985d: 174).

É exatamente este exercício nas novas percepções e reações exigidas por um aparelho técnico que Adorno vê faltar na atual música de massas, fazendo esta tecnicamente inconseqüente:

Como quer que seja no cinema, a atual música de massas pouco apresenta deste progresso no desencantamento. Neste tipo de música nada é mais forte e mais constante que a aparência externa, e nada é mais ilusório do que a objetividade (Adorno [1963] 1983b: 188).

Mesmo assim o autor acredita ser possível uma música de massas tecnicamente conseqüente, que chama de música artística, capaz de fugir à rotina do sempre igual, mesmo que para isso ela perca as características que a torna aceita pelas massas; isto é, o momento de sua produção, orientada com vistas a respeitar a autonomia da exigência expressiva e da lógica do objeto, procura se esquivar das leis de produção de bens para o mercado.

Se estendermos o raciocínio de Adorno seria possível dizer que, entre todas as músicas adequadas a apercepção em estado de descontração, somente na música artística a técnica de reprodução produz efeitos comparáveis aos que Benjamin vê no cinema, ou seja, a experiência do inconsciente auditivo. Mas para que tal experiência seja possível, para que a inovação 
técnica permita este acesso, é necessária uma nova atitude, um adestramento da percepção do homem contemporâneo, sendo capaz de se colocar em descontração. Assim percebemos que não é possível uma reflexão sobre a técnica, por mais autônoma que seja, que não considere também uma educação do corpo, ou melhor, que não considere as atitudes exigidas pelo aparelho técnico.

Vista desse ângulo, e por mais paradoxal que possa parecer, essa discussão encontra ressonância também nas preocupaçóes de Marcel Mauss apresentadas em seu "Técnicas do corpo" ([1950] 2003), uma vez que toda a reflexão apresentada ali parte da observação empírica sobre as variaçóes de atitude que os homens apresentam, de sociedade em sociedade, no emprego de suas técnicas. Em busca de tal ressonância que iniciamos o terceiro e último momento deste trabalho.

\section{Com Benjamin e Mauss: corpo, técnica e sociedade}

Uma boa maneira de iniciar o diálogo entre as idéias de Marcel Mauss e Walter Benjamin talvez seja indagar como o primeiro classificaria, de acordo com suas propostas para o estudo d'“As técnicas do corpo" ([1950] 2003a), aquela atitude apresentada pelo examinador distraído, vendo aí o produto da aplicação de uma possível técnica da descontração.

Nessa comunicação feita à Sociedade de Psicologia em 1934 e publicada no ano seguinte pelo Journal de Psychologie, Marcel Mauss expóe aquilo que vê como um novo campo de estudos a ser explorado: o das técnicas do corpo. Após apresentar como entende a noção (ato tradicional eficaz; série de atos montados no indivíduo, por sua educação e pela sociedade, com a finalidade de adaptar o corpo ao seu uso, e que podem ser ordenados num sistema de montagens simbólicas), Mauss faz uma longa consideração sobre as maneiras de se classificar tais técnicas (por sexo e idade, rendimento e transmissão; ou ainda pela enumeração biográfica, pela distribuição ao longo do curso de vida do indivíduo), concluindo com consideraçóes gerais acerca do exposto anteriormente. Vale lembrar que, neste clássico da antropologia, mais do que elaborar a teoria geral das técnicas do corpo que diz ser possível, Mauss apresenta uma espécie de plano de trabalho aos etnógrafos, indicando aquilo que se está por fazer para que tal teoria possa entáo ser levada a cabo. De certa maneira, ao nos debruçarmos sobre a atividade descontraída, a atitude desconcentrada do espectador/ouvinte descrita por Walter Benjamin, ${ }^{14}$ procuramos retomar esta velha pauta de trabalho.

Para que o indivíduo se torne um examinador distraído, se coloque em descontração, é preciso o adestramento da percepção, a educação de seus sentidos, em suma, de seu corpo. Dessa forma, e seguindo os princípios de classificação inicialmente propostos por Mauss, a técnica da descontração poderia ser abordada do ponto de vista da natureza de sua educação e adestramento, da transmissão da forma das técnicas:

4) transmissão da forma das técnicas. - Último ponto de vista: o ensino das técnicas sendo essencial, podemos classificá-las em relação à natureza dessa educação e desse adestramento. E eis aqui um novo campo de estudos: incontáveis detalhes inobservados, e cuja observação deve ser feita, compóem a educação física de

14. Lembramos que Benjamin, na primeira versão do ensaio sobre a arte tecnicamente reprodutível ([1936] 1985d), tece consideraçôes sobre a reprodução técnica da música pelos discos, numa analogia à técnica cinematográfica, comentários que estão ausentes na segunda versão. De qualquer forma, e pelo exposto anteriormente, já devemos estar autorizados a afirmar que espectador e ouvinte apresentam a mesma atitude desconcentrada, seja diante do filme ou do disco. 
todas as idades e dos dois sexos (Mauss [1950] 2003a: 411).

Como havia apontado Walter Benjamin, o cinema cumpre a funçáo de educar os sentidos para a descontração, já que

O filme serve para exercitar o homem nas novas percepçóes e reaçóes exigidas por um aparelho técnico cujo papel cresce cada vez mais em sua vida cotidiana (Benjamin [1936] 1985d: 174).

É possível perceber, na enumeração biográfica das técnicas do corpo apresentada por Mauss, que o ensino técnico dos indivíduos inicia-se na mais tenra idade e se prolonga até a idade adulta, tendo seu momento decisivo na adolescência, sobretudo nos ritos de iniciação. Quanto às técnicas da idade adulta especificamente - que nos interessam aqui -, o autor diz ser possível distinguir entre técnicas do sono e da vigília e, nesta, entre atividade e repouso, podendo este último ser ativo ou passivo, frisando que as técnicas de repouso ativo dizem respeito não só à estética, mas também aos jogos do corpo (Mauss [1950] 2003a).

Dito isto, e aceitando que a descontração característica do examinador distraído de Benjamin é alcançada por meio de um adestramento técnico, de uma educaçáo dos sentidos, a técnica da descontração poderia ser abordada não só pela forma de sua transmissão, mas também como uma das técnicas da vigília do repouso ativo. Dessa maneira, a formulação paradoxal de um examinador distraído encontra seu princípio de classificação na formulação não menos paradoxal de uma atividade realizada em repouso, repouso ativo. Mas por que paradoxal?

Como apontou Marcel Mauss ao apresentar as técnicas da vigília, inicialmente atividade e repouso encontram-se em oposição:
3) Técnicas da atividade, do movimento. - Por definição, o repouso é a ausência de movimentos, o movimento, a ausência de repouso ([1934] 2003a: 416).

Mesmo iniciando sua argumentação sobre as técnicas da vigília contrapondo atividade e repouso, é possível perceber que ele substitui o primeiro termo por movimento. Tal substituição, que poderia passar despercebida, revela algo importante na sua argumentação: se o repouso não é mais ausência de atividade, mas de movimento, então a ausência de movimento, que é o repouso, náo exclui a atividade. $\mathrm{Ou}$ seja, sem tal operação seria impossível considerar toda uma série de atividades que perpassam os momentos de repouso, da alimentaçáo à conversação, mas sobretudo as atividades estéticas e os jogos do corpo, sendo os dois últimos associados mais diretamente ao que Mauss chamou de repouso ativo. Também a apercepção desconcentrada de um filme é uma atividade realizada em repouso, já que sua fruição estética só é possível na medida que o espectador esteja distraído, como defendeu Walter Benjamin contra os críticos de arte de sua época, incapazes de ver na descontração a possibilidade de uma atitude crítica.

Para exemplificar uma atividade estética realizada no repouso ativo, Mauss apresenta a noção de dança do repouso, partindo da divisão proposta por von Hornbostel e Curt Sachs entre danças de repouso e danças de açáo. Ao mesmo tempo em que admite esta divisão, aponta que os autores são vítimas do mesmo erro fundamental em que vivia parte da sociologia naquele tempo, qual seja, acreditarem que as sociedades se repartiriam em sociedades de descendência masculina ou descendência uterina, associando assim danças de ação às primeiras e danças de repouso às outras. Afirma ainda que Sachs (1933) classificou um pouco melhor tais danças em extrovertidas e introvertidas, dizendo entáo que 
Estamos em plena psicanálise, provavelmente bastante fundamentada aqui. Em verdade, o sociólogo deve ver as coisas de modo mais complexo ([1950] 2003a: 417).

Deixando de lado a polêmica em torno de sociedades e descendências, é possível indagar: por que Mauss diz que estamos em plena psicanálise? E o que quer dizer quando afirma que o sociólogo deve ver as coisas de modo mais complexo?

Recorremos mais uma vez a Claude LéviStrauss. Como dito anteriormente, na sua "Introdução à obra de Marcel Mauss" ([1950] 2003), este aponta como uma das características fundamentais do modernismo do seu antecessor, o fato de Mauss ter indicado a aproximaçáo entre etnologia e psicanálise, expressa sobretudo no recurso às noçóes de categoria inconsciente e de categoria do pensamento coletivo, chamando a atenção para a especificidade do uso que faz na análise etnológica:

O problema etnológico é portanto, em última análise, um problema de comunicação; e essa constatação deve bastar para separar radicalmente esta via seguida por Mauss, identificando inconsciente e coletivo, da de Jung (...). Pois não é a mesma coisa definir o inconsciente como uma categoria do pensamento coletivo ou distinguílo em setores, conforme o caráter individual ou coletivo do conteúdo que se lhe atribui (LéviStrauss [1950] 2003: 29).

Assim, ao mesmo tempo em que Mauss se aproxima da psicanálise recorrendo à noção de inconsciente, ele se afasta ao associá-la a pensamento coletivo, e muito provavelmente o faz por acreditar que os atos praticados pelos indivíduos, mais do que mera expressão $\mathrm{da}$ educação individual, trazem as marcas da sociedade em que estão inseridos, devendo assim ser abordados da perspectiva do homem total. ${ }^{15}$

Em Benjamin trata-se da mesma operação, lidando também com um problema de comunicação: tanto o inconsciente de que fala é coletivo - inconsciente óptico da sociedade contemporânea - quanto a atitude desconcentrada do examinador distraído não é expressão apenas do comportamento individual, mas reveladora também das condiçóes sociais de uma época determinada. Desta maneira é possível perceber a aproximação estabelecida por Walter Benjamin entre crítica de arte e psicanálise como similar à que Mauss propôs entre esta $\mathrm{e}$ a etnologia: assim como Benjamin percebe no cinema, enquanto obra tecnicamente reprodutível, uma linguagem capaz de dar acesso ao inconsciente óptico da sociedade moderna, Mauss vê nas técnicas do corpo uma linguagem que permite acompanhar a atividade do inconsciente.

Antes de passarmos às consideraçóes finais, há ainda uma distância entre as idéias de Mauss e Benjamin que precisa ser superada aqui: pois se o primeiro trata de uma tecnologia sem instrumentos, o outro está falando de uma tecnologia com instrumentos. Esta distância deve ser percorrida, indicando os caminhos que ligam os dois pontos.

É o próprio Mauss quem nos oferece o termo mediador entre estas aparentemente diferentes tecnologias. Pois se ele adverte que é preciso não incorrer no erro de achar que só há técnica onde há instrumento, cuidado que o fez empreender toda a enumeraçáo e descrição daquela infinidade de técnicas corporais, isso não significa que dê pouca importância às técnicas onde há instrumentos. Pelo contrário,

15. Esta noção foi discutida por Mauss dez anos antes, em outra comunicação feita à mesma Sociedade de Psicologia e publicada no Journal de Psycologie et Pathologique: "Relaçóes reais e práticas entre a psicologia e a sociologia" ([1950] 2003b). 
e deixando de lado o recurso ao cinema para explicar como o modo de caminhar de suas enfermeiras americanas migrou para o corpo das moças nas ruas de Paris, Mauss chega a cunhar um termo para designar tal arranjo: a formaçáo de pares mecânicos com o corpo, alvo de um estudo dos movimentos mecânicos que, segundo ele, já vinha sendo empreendido por Reulaux e Farabeuf, demonstrando a relevância do tema. Mesmo assim, é inconteste a precedência que dá para as primeiras, já que, nas suas palavras, "antes das técnicas de instrumentos, há o conjunto das técnicas do corpo" (Mauss [1950] 2003a: 407).

Mesmo que Walter Benjamin esteja nos falando da mais emancipada de todas as técnicas, a reprodução técnica, e mesmo tendo dito que a fotografia só revelou suas verdadeiras potencialidades no momento que o rosto humano deixou de figurar em seu centro, ele não negaria a precedência do corpo, de suas técnicas. Pelo contrário, pois todas as energias revolucionárias contidas no cinema dissipariam no ar se antes o espectador não fosse capaz de se colocar em descontração.

Enquanto um habitus ${ }^{16}$ - pois é disto que se trata! - a atitude desconcentrada não é só fruto da educação individual do espectador que se distrai, mas também das condições sociais de uma época, de uma sociedade cuja técnica é a mais emancipada jamais vista e que, por isso mesmo, se confronta com a sociedade na forma de uma segunda natureza, tão elementar quanto a primeira, obrigando ao homem contemporâneo o aprendizado das novas percepçóes e reaçóes exigidas pelo aparelho técnico de nosso tempo, tornando-se assim objeto das inervaçóes humanas. Assim, por mais autônoma que a técnica se apresente, capaz de iludir quanto a sua

16. Vale lembrar que a noção de habitus é aqui entendida na acepção de Marcel Mauss ([1950] 2003a), não levando em conta os usos ulteriores que teve, como em Pierre Bourdieu, por exemplo. essência humana, como se operasse sem a agência dos homens, no fim das contas é ao corpo que ela novamente se dirige, exigindo uma nova atitude, uma educaçáo dos seus sentidos.

Em suma, e da mesma maneira que Benjamin havia apontado para uma superação dialética entre a sua posição e a de Adorno na análise do filme sonoro, é possível dizer que o enfoque na formaçáo de pares mecânicos poderia oferecer a mesma mediação entre a perspectiva sem instrumentos de Mauss e a perspectiva com instrumentos de Benjamin. E isto porque, tanto não é possível tratar das técnicas do corpo sem fazer referência aos instrumentos, como é impossível falar da reprodução técnica sem lembrar do corpo. De qualquer maneira, nos dois casos trata-se de

(...) ver técnicas e a obra da razão prática coletiva e individual, lá onde geralmente se vê apenas a alma e suas faculdades de repetição (Mauss [1950] 2003a: 404).

\section{Etnografia da música, disco e incons- ciente auditivo}

Resta-nos agora a difícil tarefa de tentar responder ao problema posto no início: seria possível ver a ilusão auditiva produzida pelos meios técnicos emancipados como parte integrante do fazer musical contemporâneo, e assim trazer os discos para o foco central de uma etnografia da música, vendo neles algo mais que ferramentas para o teste de hipóteses? Talvez mais que propriamente dar uma resposta, gostaríamos de indicar como esta constelaçáo inusitada de autores pode ajudar na construçáo de uma estratégia reflexiva alternativa para o enfrentamento da questáo.

Como vimos com Anthony Seeger (1992) e John Blacking (1995), tal compatibilização seria extremamente problemática, já que o efeito ilusório dos meios técnicos impediria o acesso 
ao fazer musical. Com o perdão da palavra, chega a parecer ingênuo pensar que uma pessoa, ao se distrair ouvindo um bom disco, acredite mesmo que aqueles sons reproduzidos pelo seu equipamento estejam sendo realizados sem a agência humana. De qualquer maneira, há de fato uma ilusão operando ali, já que o ouvinte é confrontado com o produto da atividade humana, da sua própria atividade, mas de forma emancipada, isto é, como produto alienado do trabalho humano, como já diria Karl Marx.

Buscando então superar a dificuldade apontada por Seeger e Blacking, Walter Benjamin ([1936] 1985d; [1955] 1992) nos oferece como alternativa encarar os meios técnicos atentando para a diferença entre linguagem do equipamento de registro e linguagem do corpo humano. Desta perspectiva o disco, enquanto obra de arte tecnicamente reprodutível, não só exige uma nova atitude - a descontração - de seu ouvinte, como permite acompanhar um espaço sonoro que passa a ser preenchido inconscientemente - o inconsciente auditivo. Com isto a ilusão auditiva, a auto-alienação humana diante de um aparelho técnico emancipado, torna-se produtiva, já que

Com a representação do homem pelo aparelho, a auto-alienação humana encontrou uma aplicação altamente criadora (Benjamin [1936] 1985d: 180),

pois não só exige do homem contemporâneo uma nova atitude crítica diante das obras que reproduz, como também, nesta mudança, revela as condiçóes sociais de sua época. $\mathrm{Ou}$ ainda, para usar os termos dos dois primeiros, a ilusão auditiva produzida pelos meios técnicos provoca alteraçóes na concepção, na execução e na apreciação das músicas que reproduz: mais que iludir, demonstra uma outra maneira de fazer e ouvir música utilizada pelos membros de uma sociedade determinada.
Mas se saímos pelas portas dos fundos da etnografia da música para nos arriscar em certas veredas tortuosas da teoria crítica, faltava ainda uma base empírica, se podemos dizer assim, um lugar de onde se pudesse acompanhar o adestramento da percepçáo exigido pela ilusão auditiva característica da reprodução técnica da música, e que nos trouxesse de volta aos caminhos da antropologia. E é Marcel Mauss que oferece pistas indicativas de um tal lugar.

Como procuramos salientar anteriormente, a aparente contradição entre tecnologia sem instrumentos em Mauss e tecnologia com instrumentos em Benjamin encontraria sua possível superação dialética enfocando a formação de pares mecânicos entre corpo e instrumento, onde a atitude desconcentrada exigida pelos meios técnicos emancipados é tomada como produto de uma técnica da descontração, uma atividade realizada em repouso, uma técnica do repouso ativo, fruto de um empreendimento que é ao mesmo tempo individual e social.

É verdade que o inesperado recurso a Marcel Mauss não basta para garantir a base empírica necessária para se levar a cabo uma etnografia da música que incorpore o disco, náo apenas como instrumento de trabalho, mas também como objeto da observaçáo. Tal garantia só será dada à medida que avançarem as etnografias dos usos sociais e da produção social dos discos, preenchendo aquela lacuna etnomusicológica que procuramos evidenciar anteriormente. Acompanhar como a ilusão auditiva opera criativamente no fazer musical contemporâneo, alterando a concepçáo, a execuçáo e a apreciação da música tecnicamente reprodutível, talvez seja uma boa maneira de, quiçá, rastrear algumas daquelas "luas mortas, ou pálidas, ou obscuras, no firmamento da razão” (Mauss [1950] 2003b: 343). 


\section{Referências bibliográficas}

ADORNO, Theodor Wiesengrund. [1959]. "Idéias para a sociologia da música". In Textos escolbidos/Walter Benjamin, Max Horkheimer, Theodor W. Adorno, Jürgen Habermas; traduçôes de José Lino Grünnewald... [et al.]. 2a edição. São Paulo: Abril Cultural, 1983a.

[1963]. "O Fetichismo na música e a regressão da audição". In Textos escolhidos/Walter Benjamin, Max Horkheimer, Theodor W. Adorno, Jürgen Habermas; traduçôes de José Lino Grünnewald... [et al.]. $2^{2}$ edição. São Paulo: Abril Cultural, 1983b.

1994. "Theodor Adorno Letters to Walter Benjamin". In Aesthetics and Politics/Ernst Bloch, Georg Lukács, Bertold Brecht, Walter Benjamin, Theodor Adorno; translation editor Ronald Taylor; afterword by Fredric Jameson. London, New York: Verso.

BENJAMIN, Walter. [1929]. "O surrealismo - o último instantâneo da inteligência européia”. In Magia e técnica, arte e politica - Ensaios sobre literatura e história da cultura; tradução de Sérgio Paulo Rouanet e prefácio de Jeanne Marie Gagnebin. São Paulo: Editora Brasiliense, 1985a.

. [1931]. "Pequena história da fotografia". In Magia e técnica, arte e politica - Ensaios sobre literatura e história da cultura; traduçáo de Sérgio Paulo Rouanet e prefácio de Jeanne Marie Gagnebin. São Paulo: Editora Brasiliense, 1985b.

[1934]. "O autor como produtor". In Magia e técnica, arte e politica - Ensaios sobre literatura e história da cultura; tradução de Sérgio Paulo Rouanet e prefácio de Jeanne Marie Gagnebin. São Paulo: Editora Brasiliense, 1985c.

. [1936]. "A obra de arte na era da sua reprodutibilidade técnica ( $1^{\text {a }}$ versão)". In Magia e técnica, arte e política - Ensaios sobre literatura e história da cultura; tradução de Sérgio Paulo Rouanet e prefácio de Jeanne Marie Gagnebin. São Paulo: Editora Brasiliense, 1985 d.

. [1955]. "A obra de arte na era da sua reprodutibilidade técnica (2 $2^{a}$ versão)”. In Sobre Arte, técnica, linguagem e politica; tradução de Maria Luz Moita. Lisboa: Relógio D’Água Editores, 1992.

. 1994. "Walter Benjamin Reply" In Aesthetics and Politics/Ernst Bloch, Georg Lukács, Bertold Brecht, Walter Benjamin, Theodor Adorno; translation editor Ro- nald Taylor; afterword by Fredric Jameson. London, New York: Verso.

BLACKING, John. 1995. "Music, Culture and Experience" In Music, Culture \& Experience - Selected papers of John Blacking; edited and with an introduction by Reginald Byron; foreword by Bruno Nettl. Chicago and London: University of Chicago Press.

CARVALHO, José Jorge de. 1999. "Transformações da sensibilidade musical contemporânea” In Horizontes Antropológicos - música e sociedade, Porto Alegre, no. 11, p. 53-91.

COHN, Gabriel. 1986. "Adorno e a teoria crítica da sociedade" In Theodor W. Adorno - Sociologia; organização e introdução de Gabriel Cohn; tradução de Flávio R. Kothe, Aldo Onesti e Amélia Cohn. São Paulo: Editora Ática.

Grande Dicionário Larousse Cultural da Lingua Portuguesa. São Paulo: Nova Cultural, 1999.

KOTHE, Flávio René. 1975. Benjamin e Adorno: um confronto. Tese de doutorado em teoria literária e literatura comparada. São Paulo: FFLCH/USP. (Publicada em livro com o título Benjamin \& Adorno: confrontos. São Paulo: Ática, 1978.)

LÉVI-STRAUSS, Claude. [1950]. "Introdução à obra de Marcel Mauss". In Mauss, Marcel. Sociologia e Antropologia. São Paulo: Cossac \& Naify, 2003.

[1950]. "As Técnicas do Corpo". In Sociologia e Antropologia. São Paulo: Cosac \& Naify, 2003a.

MAUSS, Marcel. [1950]. "Relaçôes reais e práticas entre a psicologia e a sociologia". In Sociologia e Antropologia. São Paulo: Cosac \& Naify, 2003b.

ROUANET, Sérgio Paulo. 1981. Édipo e o anjo: itinerários freudianos na obra de Walter Benjamin. Rio de Janeiro: Editora Brasiliense.

SACHS, Curt. 1933. Weltgeschichte des Tanzes. Berlim.

SEEGER, Anthony. 1992. "Ethnography of Music" In Ethnomusicology: an introduction; edited by Helen Myers. London: The Maximillan Press. ("Etnografia da música". In: Sinais Diacríticos: música, sons e significados. Tradução de Giovanni Cirino, com uma nova introdução de Anthony Seeger. No. 1. São Paulo: Departamento de antropologia/FFLCH/USP, 2004.)

WEBER, Max. [1911]. Os Fundamentos Racionais e Sociológicos da Música; tradução, introdução e notas de Leopoldo Waizbort; prefácio de Gabriel Cohn. São Paulo, EDUSP, 1995. 